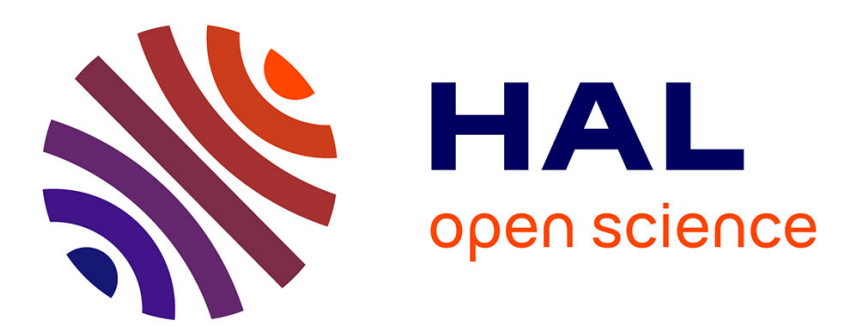

\title{
Real-time mobile monitoring of bipolar disorder: a review of evidence and future directions
}

\author{
Gideon Dunster, Joel Swendsen, Kathleen Ries Merikangas
}

\section{To cite this version:}

Gideon Dunster, Joel Swendsen, Kathleen Ries Merikangas. Real-time mobile monitoring of bipolar disorder: a review of evidence and future directions. Neuropsychopharmacology, 2020, 46 (1), pp.197208. 10.1038/s41386-020-00830-5 . hal-03091001

\section{HAL Id: hal-03091001 https://hal.science/hal-03091001}

Submitted on 7 Jan 2021

HAL is a multi-disciplinary open access archive for the deposit and dissemination of scientific research documents, whether they are published or not. The documents may come from teaching and research institutions in France or abroad, or from public or private research centers.
L'archive ouverte pluridisciplinaire HAL, est destinée au dépôt et à la diffusion de documents scientifiques de niveau recherche, publiés ou non, émanant des établissements d'enseignement et de recherche français ou étrangers, des laboratoires publics ou privés. 


\title{
NEUROPSYCHOPHARMACOLOGY REVIEWS Real-time mobile monitoring of bipolar disorder: a review of evidence and future directions
}

\author{
Gideon P. Dunster (D) ${ }^{1}$, Joel Swendsen ${ }^{2}$ and Kathleen Ries Merikangas ${ }^{1,3}$
}

Rapidly accumulating data from mobile assessments are facilitating our ability to track patterns of emotions, behaviors, biologic rhythms, and their contextual influences in real time. These approaches have been widely applied to study the core features, traits, changes in states, and the impact of treatments in bipolar disorder (BD). This paper reviews recent evidence on the application of both passive and active mobile technologies to gain insight into the role of the circadian system and patterns of sleep and motor activity in people with BD. Findings of more than two dozen studies converge in demonstrating a broad range of sleep disturbances, particularly longer duration and variability of sleep patterns, lower average and greater variability of motor activity, and a shift to later peak activity and sleep midpoint, indicative of greater evening orientation among people with BD. The strong associations across the domains tapped by real-time monitoring suggest that future research should shift focus on sleep, physical/ motor activity, or circadian patterns to identify common biologic pathways that influence their interrelations. The development of novel data-driven functional analytic tools has enabled the derivation of individualized multilevel dynamic representations of rhythms of multiple homeostatic regulatory systems. These multimodal tools can inform clinical research through identifying heterogeneity of the manifestations of BD and provide more objective indices of treatment response in real-world settings. Collaborative efforts with common protocols for the application of multimodal sensor technology will facilitate our ability to gain deeper insight into mechanisms and multisystem dynamics, as well as environmental, physiologic, and genetic correlates of BD.

Neuropsychopharmacology (2021) 46:197-208; https://doi.org/10.1038/s41386-020-00830-5

\section{INTRODUCTION}

The potential of digital technologies for deepening understanding of the etiology, risk factors, and course of mental disorders, as well as informing their intervention and prevention, is becoming increasingly apparent. Researchers are now seeking to quantify the lived experience of those with mental health conditions through capturing real-time information from a myriad of sensors on smartphones and connected devices, making digital health one of the fastest-growing areas of both research and commercial development. These technologies are particularly valuable in supplementing traditional clinical assessments that are inherently retrospective in nature. They may also inform real-time manifestations and interrelations among domains of relevance to mental health and enhance the delivery of evidence-based treatments that may help to close the growing gap in access to mental health care.

The application of mobile assessment tools has enriched our understanding of mental disorders that may fluctuate rapidly over time, in particular bipolar disorder (BD). Tracking of mood symptoms on a daily basis has a long history that predates the digital tools that are now commonplace in psychiatric research. Prospective daily ratings of the symptoms of $\mathrm{BD}$ were pioneered by life charting tools developed by Post et al. [1, 2], who tracked changes in symptoms and states in hundreds of patients over periods of a year or longer. The widespread availability of mobile tools has dramatically enhanced the feasibility of these earlier paper and pencil methods that were both time-consuming and analytically challenging.

This paper summarizes evidence on the application of mobile technologies to gain insight into the role of the circadian system and patterns of sleep and motor activity in people with BD. The aims are to (1) provide background on both passive and active mobile assessments in BD; (2) review the evidence for the roles of sleep, motor activity, and circadian rhythms based on actigraphy in BD and update earlier reviews of this body of research; (3) summarize evidence from studies of active monitoring of BD using ecological momentary assessment (EMA); (4) describe the methodologic and analytic challenges to the administration and interpretation of mobile technologies in BD; and (5) propose recommendations for the future application of mobile tracking to study mood disorders and related conditions.

\section{BACKGROUND: MOBILE ASSESSMENTS}

Mobile assessments fall into two broad categories that can characterize the frequency and variability of specific daily experiences: (1) passive or objective monitoring that automatically collects data on physical states such as motor activity, heart rate, temperature, and other physiological variables, and behavioral data that capture physical location, patterns of smartphone usage and speech patterns; and (2) active monitoring through

\footnotetext{
${ }^{1}$ Intramural Research Program, National Institute of Mental Health, Bethesda, MD, USA; ${ }^{2}$ University of Bordeaux, National Center for Scientific Research; EPHE PSL Research University, Bordeaux, France and ${ }^{3}$ Johns Hopkins Bloomberg School of Public Health, Baltimore, MD, USA

Correspondence: Kathleen Ries Merikangas (merikank@mail.nih.gov)
}

Received: 22 May 2020 Revised: 17 July 2020 Accepted: 30 July 2020

Published online: 12 September 2020 
198

smartphones and other devices that require intentional recording of subjective experiences and states such as through EMA.

\section{Passive assessments: actigraphy}

The use of passive mobile assessments has grown exponentially in the mental health field because of the increasing recognition of the role of sleep and physical activity in the etiology or exacerbation of specific disorders. Actigraphy, which quantifies motor activity using a wrist-worn device that contains an accelerometer measuring movement/acceleration, has been used for more than two decades as an objective measure of sleep that offers an alternative to the cumbersome and expensive methods of polysomnography. It is the most widely used passive measure to study traits and disorders of sleep and motor activity, particularly for BD and attention-deficit hyperactivity disorder (ADHD) [3-5]. The validity of actigraphy as an index of sleep has been systematically studied [6]. According to the guidelines of professional sleep societies $[7,8]$, valid estimation of sleep by actigraphy also requires sleep diaries that facilitate the defining of sleep onset, offset, midpoint, and other measures derived from actigraphy.

Actigraphy-based differences in patterns of sleep and/or motor activity have been particularly prominent in studies of mood disorders $[9,10]$, but such differences have also been evident in samples of people with psychosis [3, 11, 12], substance use disorders [13], and ADHD [14]. While actigraphy has been most widely used to study sleep patterns in people with BD, there has been a growing focus on patterns of motor activity that also are a central feature of BD [9].

There are now several large population-based studies that have included actigraphy, including the UK Biobank $[15,16]$, the National Health and Nutrition Examination Study in the US [17] and the adolescent brain cognitive development (ABCD) [18]. There has also been a rapid growth of other passive measures employed to track multiple domains in people with BD, such as speech patterns $[19,20]$. Smartphones and many wearable sensors are able to collect user data, such as location via GPS and voice data from conversations and social metrics, via call and text logs $[21,22]$. These trackers are being increasingly combined to provide a comprehensive assessment of the regulation of multiple systems simultaneously [23-25]. However, recent systematic reviews of mobile apps for $B D$ have concluded that, to date, few of the apps follow practice guidelines or established methodologic standards for either symptom tracking, prediction, or management of these conditions $[26,27]$.

Active assessments: ecological momentary sampling (EMA) One important limitation in the interpretation of data acquired through passive monitoring is the lack of contextual information on variables that may influence the sleep, activity, or mood changes inferred from speech, texting, GPS location, or other interactive influences with mobile devices. Although many studies do include subjective symptom ratings with passive monitoring, most of this work is based on retrospective reporting of symptoms across the week or month. Gaining insight into the directional associations between events and psychological states and their association with sleep and physical activity can be enhanced through concomitant administration of tools that simultaneously capture subjective descriptions of symptoms of mood, cognition, and other subjective experience, which remain the core component of psychiatric disorders [28].

The most common technique used to collect such real-time data on daily fluctuations in emotions and other psychological states is EMA, which uses mobile devices such as smartphones to assess a range of physical and mental experiences at different moments throughout the day. The reliability and validity of EMA have been demonstrated for numerous mental conditions, including major depression, BD, suicidal ideation, anxiety disorders, schizophrenia, and drug or alcohol use disorders [2934], as well as for diverse medical conditions [35-38]. EMA reports of physical activity are more highly correlated with actigraphy data than traditional self-reports [33, 34, 39] while providing descriptive and qualitative data concerning the types of activities performed that are unavailable through actigraphy. The juxtaposition of data from actigraphy and EMA provide high-resolution characterizations of the complex interactions implicated in both physical and mental health disorders and, importantly, provide lacking information concerning the environmental or social contexts of symptom expression. There are now numerous studies that combine actigraphy and EMA with other passive measures including wearable sensors of light, temperature, galvanic skin response and heart rate to provide multimodal tracking of physical and environmental conditions experienced by the individual in the natural contexts of daily life.

\section{BACKGROUND: SLEEP AND CIRCADIAN RHYTHMS IN BIPOLAR DISORDER}

Almost all living organisms have evolved a biological timekeeping system that allows them to anticipate changes in the environment. Information from the environment, called zeitgebers (timegivers), is transmitted to these systems via input pathways that then entrain (or synchronize) the circadian clock that anticipates the 24-h day/night cycle. In humans, this system is housed in the suprachiasmatic nucleus (SCN) in the hypothalamus, with the most important zeitgeber being light, which is transmitted to the SCN via retinal input pathways. The SCN coordinates hormonal and synaptic output pathways to peripheral clocks throughout the rest of the body, similar to the conductor of an orchestra. Directly or indirectly, this system of master and peripheral clocks is responsible for timing a variety of biological functions in the human body, including sleep, physical activity, body temperature, hormone release, digestive function, and gene expression.

When working in harmony, the circadian system promotes healthy synchrony with the environment. However, disruptions at any of the levels (input, integration, output) can lead to a desynchrony internally and/or externally. Perhaps the most common example is jet lag, where crossing large longitudinal distances in short periods of time may disrupt the internal circadian system that is not accustomed to the external environment leads to sleep disruptions, among other effects. Circadian systems differ across the age span, by sex and developmental stage in youth $[40,41]$, and there is now increasing focus on circadian control of several physiologic systems [42]. Newborns traditionally do not establish a stable circadian rhythm for several months, whereas teens undergo a stereotypical delay in their circadian system during puberty, and circadian signals tend to weaken in later life. There are also significant interindividual differences in the period of endogenous circadian rhythms and their ability to entrain to the environment.

The current gold standard for inferring circadian phase involves assessing hormone release, specifically, the hormone melatonin. Melatonin is released from the pineal gland in response to signals from the SCN and can be measured through saliva, blood, or in some cases, urine samples. Traditionally, melatonin levels begin to rise around sunset and peak in the middle of the night. However, melatonin levels can be acutely suppressed by the introduction of light, including artificial light, and thus must be measured using a constant routine. Other measures, such as gene expression and heart rate variability, are also under investigation for inferring circadian phase.

Biological markers of circadian function in bipolar disorder Nearly 40 years ago, Lewy et al. [43] reported that untreated bipolar patients experiencing manic or depressed phases had a greater melatonin suppression to light at night than healthy 
controls. Similar results in untreated euthymic bipolar patients [44] led them to propose that sensitivity to light may be a marker for $B D$. The link between light and BD gained further support when it was reported that lithium, a standard treatment for bipolar disorder, diminished the light-induced suppression of melatonin in treated bipolar patients $[45,46]$. While the specific mechanism of action of lithium is still not well understood, it does alter retinal sensitivity to light [47] and may act directly on neurons in the SCN to lengthen their circadian period [48]. Given the important role of light in regulating the human circadian system, the wellestablished circadian disruptions in $\mathrm{BD}[49,50]$ (see below), and the manipulation of light as a potential treatment for BD $[43,44,46,49,51]$, it is likely that alterations in the reception and/or transmission of light may be a fundamental contributor to symptom expression in this disorder. In fact, our recent findings of an association between environmental light and both sleep and mood and anxiety disorders in a nationally representative sample of US adolescents highlight the influence of environmental contextual factors on the core domains that are dysregulated in BD [52].

Results concerning differences in the circadian release of melatonin in people with BD are inconsistent. Whereas one study found an advance in the peak phase of melatonin production in patients experiencing mania [50], other studies have found delayed phases of secretion in patients experiencing depression $[50,53]$ or euthymia [54]. Other research has shown global decreases in melatonin levels in patients with BPI regardless of stage [55]. Heterogeneity in study designs and in the assessment of melatonin may be partially responsible for discrepancies in previous results. It is also important to delineate the compared phase (when melatonin secretion begins or peaks) from amplitude (how much melatonin is secreted throughout a night). Finally, there is evidence that light-induced nighttime suppression of melatonin is greater in people with BD compared to controls [56], but that pharmacological treatment may reduce that suppression [46]. For this reason, adjustment for treatment status is important in evaluating the role of association between melatonin and BD.

There are circadian patterns of release of other biological measures such as cortisol, which peak in the morning. People with $\mathrm{BD}$ have been shown to have flatter diurnal curves and greater fluctuations in the daytime secretion of cortisol than controls [57]. Body temperature, which is under partial circadian control, also has an altered rhythm during depressive but not manic episodes [58]. There is also desynchronization of diurnal body temperature from heart rate among people with BD vs. controls [59]. Taken together, these results suggest dysregulation of circadian rhythms of multiple homeostatic regulatory systems in BD. However, potential explanations that may include a weak rhythm in the SCN, impairment in output signals to downstream SCN targets, alterations in peripheral clocks, or other mechanisms have not been well-established.

\section{FINDINGS FROM MOBILE ASSESSMENTS OF BD}

There are now over two dozen controlled studies that have employed actigraphy to track circadian rhythms and sleep in more than 1000 people with $\mathrm{BD}$, as summarized in several comprehensive reviews and meta-analyses $[3,9,10,60,61]$. The large number of variables extracted from actigraphy tap the features of three core domains: sleep, motor activity, and circadian variables. Below, we summarize findings of each of these domains from controlled studies and meta-analyses of actigraphy in people with BD, and our update of recent studies that were not included in earlier reviews of actigraphy and BD [62-65].

\section{Sleep}

Sleep has been one of the most widely studied features of people with this condition [66]. Changes in sleep duration are one of the key features of BD, but the direction of these changes is dependent on episode type. Reduced sleep need is a stereotypical characteristic of mania, and sleep deprivation can in fact trigger manic episodes [5]. There also appears to be a change in sleep architecture, as measured using EEG recordings, during manic episodes with a decrease in REM latency and an increase in REM density [67]. REM sleep is tightly controlled by the circadian system and thus, disruptions in REM directly indicate a disturbance in the circadian system during mania. Sleep disturbances are also stereotypical of depressive episodes with reductions in sleep efficiency, alterations in total sleep time, and slow-wave sleep (SWS), delays in sleep onset, and reduced time to first REM episode [68]. Sleep early in the night is typically predominated by SWS, which is tightly associated with the homeostatic drive. It is possible that during depressive episodes, sleep pressure builds more slowly, delaying the need to initiate sleep and reducing the time between sleep onset and first REM episode due to the reductions in SWS early in the night.

Changes in sleep duration have also been shown to predict changes in disease state. In one study which used self-report sleep diaries, nearly half of patients showed a change in mood on the same day or the day following a change in sleep duration with increases in sleep preceding depressive shifts and decreases preceding manic shifts [4]. Evidence from case studies has suggested that restriction of light-dark cycles ( $14 \mathrm{~h}$ light, $10 \mathrm{~h}$ dark) can stabilize mood cycles [69]; however, that schedule is not practical for many individuals. Finally, a meta-analysis of all relevant published data (regardless of the method of measuring sleep) by Ritter et al. suggests that sleep disturbances may precede the onset of $\mathrm{BD}$ by several years, beginning in puberty [70].

Aggregate findings of these studies converge in showing significantly increased sleep time, sleep latency, wake after sleep onset, and decreased sleep efficiency in samples of people with $\mathrm{BD}$ compared to controls. Two recent reviews have summarized the characteristics and results of more than 20 controlled studies of actigraphy-derived sleep parameters in BD. A meta- analysis by Tazawa et al. [61] showed differences in the sleep patterns among those with BD compared to those with MDD, particularly those in remission. In a comparison of actigraphy-derived sleep patterns in samples of people with interepisode BD vs schizophrenia, Meyer et al. [3] found that both groups exhibited greater total sleep time, time in bed, sleep latency, and wake after sleep onset, and greater variability in total sleep time than controls. However, interepisode sleep patterns in those with BD did not differ from those with schizophrenia, potentially suggesting common factors associated with these disorders. Our review of subsequent studies of BD, support the conclusions of reviews that BD individuals have longer sleep duration, but sleep more poorly as measured by wake after sleep onset (WASO) [65]. In summary, the dozens of controlled studies of actigraphy in BD have consistently demonstrated differences in sleep patterns, both during and between acute episodes. However, the extent to which these patterns are specific to BD compared to MDD or other mental disorders has not been well-established.

\section{Motor activity}

Although the importance of activation in BD has long been recognized, changes in motor activity have been relatively neglected in studies of this condition. The inclusion of changes in motor activity in the DSM-5 as a core feature of BD is supported by both clinical assessments and objective measurement through actigraphy [9]. Counterintuitively, people with $\mathrm{BD}$ tend to have a greater proportion of sedentary time than those without BD or community controls. Activity profiles also differ by age and BMI, but not sex [71]. Normative patterns of actigraphy-derived motor activity show a strong decrease in activity across age, with a dip at puberty and gradual increase to mid-adult life and a decline 
thereafter [72]. Whereas most of the studies of actigraphy in BD control for sex and age, there is lack of data on sex and age differences across development.

The aggregate evidence consistently shows decreased average activity levels among those with BD compared to controls [10]. Scott et al. [9] found that the lower mean levels of activity in BD occurred both during euthymia and depression compared with controls and other comparison groups. Moreover, BD was better characterized by greater variability than by average levels of activity. Greater levels of sedentary behavior are strongly correlated with BMI and longer time spent in depression. However, some studies have neither found significant differences in daily activity in people with euthymic BD compared to controls [61] nor in several indicators of activity [3].

Although the derived parameters from actigraphy do reflect the timing of peak activity and sleep, few of the studies of BD present descriptive data on the time of day and activity among people with BD. For example, Shou et al. [64] showed that the most significant differences in motor activity between people with BDI and controls occurred in the latter half of the day, possibly a reflection of greater eveningness in people with $\mathrm{BD}$. These somewhat inconsistent findings may therefore be a reflection of the heterogeneity of the clinical and control samples, study designs, and procedures described in earlier reviews [10].

\section{Circadian rhythms}

The circadian rhythms component of actigraphy is derived from measures that tap the timing of sleep and motor activity across the day. One of the most widely studied measures of stable characteristics of daily activity and sleep is chronotype that is a measure of the time preference for daily activities and sleep. Chronotype was first assessed with a validated questionnaire developed by Horne and Ostberg [73], with more recent measures such as the Munich ChronoType Questionnaire [74] and the Composite Scale of Morningness [8] that assess different aspects of the chronotype concept. These subjective measures of chronotype are strongly correlated with the objective actigraphy-derived midpoint of daily activity and sleep [75]. There is consistent evidence from both subjective and objective data that people with $\mathrm{BD}$ tend to have a late chronotype $[75,76]$ as well as later timing of exposure to light [65] and later timing of activity [63]. However, whether late chronotype is a trait marker, consequence, or correlate of BD has not been established. Studies of the developmental, sex, and age manifestations of chronotype will facilitate our understanding of this concept in BD [77].

Through the use of various analytical techniques, it has become possible to examine other features of circadian rhythms from actigraphy data, such as relative amplitude, interdaily stability, and intra-daily variability as measures of an individual's circadian rhythm. As the extraction and analysis of actigraphy data have advanced, so too has the application of these tools to help answer outstanding research questions with regard to both state (mania, euthymia, depression) and trait features of BD.

Similar to motor activity, several studies have compared circadian rhythm variables to differentiate mood states in individuals with the BPI subtype of BD [78, 79]. For example, one study employed actigraphy to differentiate healthy controls from euthymic individuals with BD, irrespective of subtype [80], while another used motor activity patterns to differentiate controls from euthymic individuals with BDI, BDIl, and MDD [64]. Still, other studies have focused on differentiating individuals with BD from those with other psychiatric disorders such as schizophrenia [81] or borderline personality disorder [59].

Biologic and genetic correlates of actigraphy parameters have also been examined for BD. For example, Pagani et al. [82] used actigraphy as one of a series of potential endophenotypes for BD in large extended pedigrees of people with this disorder. Vreeker [7] further examined other measures, including neuroimaging, cognitive and temperamental factors, as correlates of actigraphy parameters [7]. Other studies have investigated sleep patterns in the offspring of individuals with BD [70, 83]. Twin studies have begun to examine the components of actigraphy that may be heritable [84]. Taken together, these studies illustrate the potential of actigraphy as a research tool that may inform broader phenotypic and biologic and genetic correlates of the manifestations of BD.

\section{ANCILLARY SUBJECTIVE MEASURES: EMA}

The core components of diagnostic criteria for mental disorders are largely dependent on subjective interpretation of emotions, fears, thoughts, and changes to the "usual levels" of their underlying dimensional manifestations. Traditional clinical evaluations are prone to bias in retrospective reporting of the typical number and intensity of symptoms [85]. Moreover, the dynamic nature of mechanisms that influence the onset or severity of symptoms that may unfold over seconds, minutes, or hours rather than the periods of weeks, months, or years that are most often applied in their assessment. This is a particular concern in the diagnosis and treatment of $\mathrm{BD}$, which is characterized by emotional instability and heightened stress reactivity regardless of current clinical status [86]. While some of these temporal limitations may be overcome by certain laboratory or clinic-based paradigms, an additional concern is the ecological validity of data that are collected solely within the same environmental context. That is, observations made in controlled conditions may not fully correspond to the actual expression of clinical phenomena in daily life.

A solution to these fundamental barriers of time and context is to administer more frequent, albeit brief, assessments in real time and in the natural environments of daily life. This approach, which began with clinical research diaries in the 1940's, has evolved with mobile technologies into what is known today as EMA. While there is considerable heterogeneity in the use of this method, the typical procedure involves providing participants with a smartphone or other electronic device that prompts them to complete assessments at multiple time points throughout the day. In their reviews, Ebner-Preimer and Trull $[87,88]$ enumerate the major benefits that EMA offers, including the reduction of retrospective bias, real-time tracking of dynamic processes, simultaneous integration of multilevel data (e.g., biological, psychological), characterization of context-specific associations of behaviors and symptoms, inclusion of interactive feedback, and enhanced generalizability of results. EMA has been shown to be highly feasible and valid in the assessment of patients with mood disorders [29, 32], and in the assessment of frequently-associated conditions such as substance abuse or suicide ideation $[89,90]$.

Using EMA, studies of differences in mood between individuals with $\mathrm{BD}$ and controls have reported mixed results. One study that examined levels of positive affect (PA), negative affect (NA), and self-esteem was unable to differentiate those with $B D$ from controls. However, those with BD did have relatively high levels of within-person variability [91]. In contrast, studies by Havermans et al. reported that people with BD reported less PA and more NA than controls $[92,93]$. Similarly, two recent studies found that adults with BD reported significantly lower median mood and energy levels when compared to controls [94], and another study showed that youth with BD reported less PA and greater NA [95].

EMA studies of emotional reaction to stress in daily life in people with $\mathrm{BD}$ have also been inconsistent. While Myin-Germeys et al. [96] found that patients with BD reported larger decreases in PA than controls in response to stress, Havermans et al. [93] did not. More recently, Lamers et al. [97] found that individuals with BPI reported greater decreases in both sad and anxious mood than controls after positive events, whereas individuals with MDD only experienced greater decreases in anxious mood. By contrast, 


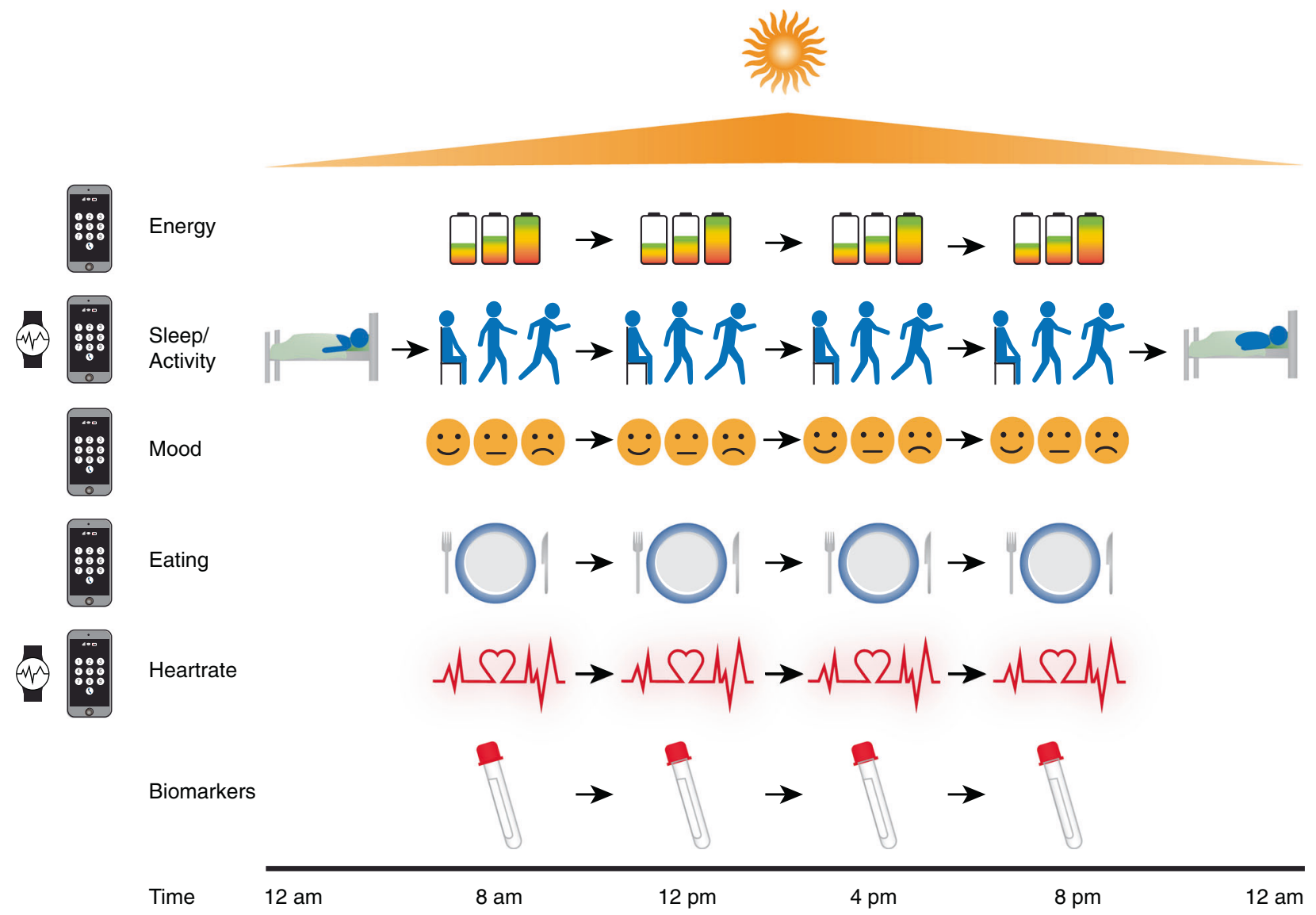

Fig. 1 Figure 1 illustrates the domains assessed in the NIMH Family Study through simultaneous objective and subjective ratings tracked in real time. Continuous objective measures of sleep and heart rate are derived from accelerometry with a wrist-worn device and analog ratings of mood, energy, anxiety and a range of other emotions, contextual information, stressors, food intake, sleep timing and quality, exercise and saliva samples are collected four times per day on a mobile phone application.

there were no changes in either anxious or sad mood in people with $\mathrm{BDI}$ following negative events. Several studies have also employed EMA to characterize additional features of BD. For example, recent research suggests that while individuals with this condition do not differ with regard to speed of thoughts or impulsivity relative to controls, they do report significantly higher variability in these domains [94]. A recent study that applied the novel methodology of fragmentation analysis as an index of the instability of mood states (see below) to EMA data from the NIMH Family Study revealed that people with BDI have greater fragmentation or instability of attention and energy, but not mood or anxiety [98]. This provided additional evidence that instability of mood may not be a core feature of this subtype of BD. By contrast, people with MDD had greater fragmentation of sad mood, as would be expected with this disorder.

The concomitant use of active and passive monitoring is a particularly valuable approach to investigate the interrelations of motor activity, sleep, circadian rhythms with mood, and other subjective states among people with BD compared to controls or other conditions, such as borderline personality disorder $[28,59,63,94]$. For example, in the National Institute of Mental Health Family Study of Affective Spectrum Disorders [28], we combined actigraphy and EMA 4 times per day to track energy, mood, sleep, and motor activity in a community-based sample that included subgroups with BD, MDD, and controls. The findings revealed bidirectional associations between motor activity and sleep and between motor activity and subjective energy, and a unidirectional association between motor activity and mood at the subsequent assessment across all participants in the study.
Among those with $\mathrm{BD}$, there was greater cross-domain reactivity in people with $\mathrm{BDI}$, suggesting that dysregulation of homeostatic balance may underlie BD [28]. These observations are consistent with the application of physical activity programs to relieve depressed mood [71]. The collection of physiologic and biologic data such as cortisol, melatonin, and heart rate measures in conjunction with actigraphy and EMA will provide greater insight into the biologic correlates of the patterns and rhythms of the manifestations of BD in daily life $[59,99]$.

The approach shown in Fig. 1 provides dynamic, real-time multilevel measures that depict their level, stability, and variability of each domain, as well as the cross-sectional and ordinal associations within and between days. The aggregate patterns of these measures can provide individualized profiles of emotional, physiological, motor activity, sleep, diet, and reactivity to daily events that may ultimately inform personalized interventions. Concomitant developments in statistical methods are providing powerful tools to analyze these intensive repeated measures multilevel functional data using structural equation modeling and functional data methods that incorporate both group and individual-level associations as described below.

\section{CHALLENGES IN INTERPRETING AND AGGREGATING MOBILE ASSESSMENTS}

Sampling and procedures

The compelling evidence for differences in patterns of daily rhythms in several mental disorders holds promise for the utility of these approaches to inform interventions, but translation is 
limited by wide variation across studies in the samples, procedures, and measures used $[9,10]$. Methodologic differences in particular have impeded our ability to summarize the aggregate evidence for patterns of activity and sleep in mood disorders, as well as their associations with psychological states, behavior, and context in real time. The most important challenge is the variation in the procedures used for the collection of mobile data, including different devices, platforms, assessment durations, and intervals.

The sample sizes included in most studies (and particularly clinical samples) are quite small, diminishing the power to fully exploit the complex network of factors involved in the domains tapped by mobile assessments. Likewise, few studies include systematic sampling procedures, and subsamples of large population registries with actigraphy are often nonrepresentative of the full sample. Although most studies have controlled for the effects of sex and age, there is a lack of information reported on sex differences in these studies, particularly across stages of development. Our earlier study showed a sex difference in the timing of motor activity, with females having significantly greater activity than males later in the day [64]. The other glaring gap in this research is the lack of diversity of the samples; race and ethnicity were rarely reported in previous studies. This is surprising in light of the evidence for strong ethnic/racial differences in circadian rhythms and sleep from population-based studies [100].

Other well-established confounders of the associations between mood disorders and actigraphy domains such as body mass index (BMI), smoking, medication use, and additional factors have not been controlled in the majority of studies using actigraphy in BD. The association between actigraphy parameters and BMI is of particular interest, as systematically investigated by Boudebesse et al. [78]. In addition, many studies that have employed actigraphy as an index of sleep do not include the sleep diary questions that are recommended by the guidelines of professional sleep and biologic rhythms societies $[7,8]$.

\section{Analytic challenges and innovation}

A review of traditional statistical methods in actigraphy and sleep studies of people with BD has been recently summarized by the Circadian Rhythms Task Force of the International Society for Research in BD [60]. Some limitations in current analytic approaches of actigraphy data include the parametric methods used to analyze actigraphy data due to the restrictive assumptions of many of the derived parameters, different methods for combining the minute-to-minute data derived from actigraphy across days and weeks, and differences in within-day compared to cross-day summaries that are often not incorporated in the analyses or presentation of the data. A spectrum of novel "functional" data analysis (FDA) [101] methods have recently been developed that are fully data-driven without the required parametric assumptions about the functional form of diurnal patterns required by most traditional actigraphy analytic methods. Here, "functional" is a term reflecting the idea that epoch-byepoch actigraphy counts can be thought of as "curves" representing persons' rest/activity patterns over 24-h periods. Techniques such as functional principal component analysis (FPCA) [17, 102], multilevel functional principal component analysis (MFPCA) [12], function-on-scalar regression (FOSR) [103], and generalized function-on-scalar regression (gFOSR) [104] that combines both MFPCA and FOSR [105] have provided more powerful approaches to capture the intense repeated measures data extracted from actigraphy. Application of these approaches to the growing body of actigraphy data on $\mathrm{BD}$, particularly with the growing effort to combine data across studies, will have more power to represent the daily, weekly, seasonal, and annual patterns of sleep, physical activity, and circadian rhythms in this disorder.
An important challenge for researchers on BD concerns the difficulty in selecting the most pertinent parameters derived by actigraphy from among the highly numerous metrics generated from this technology. This difficulty is complicated even further by the frequent lack of a priori hypotheses concerning how specific metrics may be related to BD symptoms. Most studies that have investigated genetic factors associated with actigraphy parameters have examined dozens of derived features individually, sometimes with a false discovery or other correction for multiple testing. However, these findings may be misleading because of the high intercorrelations among the actigraphy metrics. The use of the joint and individual variance explained (JIVE) [106] method, a data reduction technique for multivariate data on multiple domains, estimates the joint and individual variance explained by the three domains derived from actigraphy, sleep, activity, and circadian rhythmicity. These features are estimated through integrative analyses that decompose the data into a low-rank approximation that estimates the portion of variance that is shared across the three domains as well as specific to each. Due to its capacity to integrate complex relations within and between domains, the JIVE regression generally results in a higher area under the curve and a greater percentage of variance explained.

In Fig. 2, we illustrate the application of this novel technique to actigraphy data collected from 311 adult participants with a range of mood disorder subtypes and controls who participated in the National Institute of Mental Health Family Study of Affective Spectrum Disorders [28]. We applied JIVE to the NIMH Family Study actigraphy data in order to identify the joint and individual variance explained by the three features of activity including physical activity, sleep, and circadian rhythmicity. Figure 2 shows the individual variance explained by these features of actigraphy. Joint variation explained $57 \%$ for the variance of sleep, $84.6 \%$ of the variance of physical activity, and $49.8 \%$ of the variance of circadian rhythmicity. The high levels of joint variation indicates the substantial overlap across these three domains that have generally been considered independently in research on BPD. Regression analyses of the JIVE scores showed that people with $\mathrm{BDI}$ differed significantly from controls on the joint score that loaded for the average and variability of motor activity and intra-

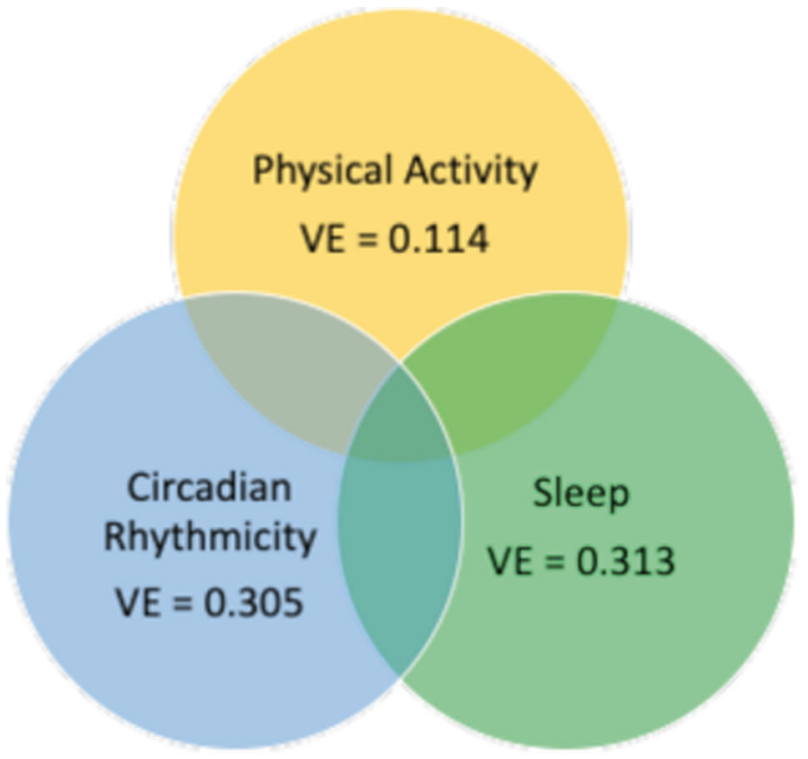

Fig. 2 Individual variation from application of JIVE to the NIMH Family Study actigraphy data. The individual variation attributable to sleep features was $31.3 \%$, circadian rhythm variables was $30.5 \%$, and physical activity $11.4 \%$. 
daily variability of circadian rhythmicity $(C R)$ feature (intra-daily variability), but not on the individual or joint factors involving sleep parameters. Of interest, there were no significant differences for people with either BD- II or MDD compared to controls.

Likewise, analytic tools that represent the multilevel intensive time series data collected in the within- and between-day ratings on EMA devices also have some limitations in terms of assumptions and multiple testing. One novel framework that was recently introduced for EMA data application is fragmentation modeling that quantifies the stability/instability or fragmentation of standardized trajectories of emotional states. This procedure applies a two-step approach that first normalizes participant-level scores and then dichotomizes states inside and outside a range of 1 standard deviation as an index of stability (less fragmentation) or instability (more fragmentation) of assessed domains [98]. There are also substantial ongoing efforts to adapt structural equation modeling and other statistical tools for such high intensity multilevel repeated measures data that may improve our ability to characterize and predict changes in multilevel dynamic states that can now be tracked with mobile technologies.

Considerable variation is observed in the number of days of monitoring for both the active and passive assessments covered in this review. The average duration of EMA studies was 8.2 days (range: 6-14 days). The average duration of the recent actigraphy studies covered in this review was 25.5 days (range: 14-50 days), which represents an increase in homogeneity relative to the range for studies included in previous reviews (1-56 days). Within-day variability is a particular concern for EMA studies, which ranged from two to ten assessments per day for subsequent studies reviewed here. However, this variation is explained by the fact that discreet and rapidly fluctuating phenomena (such as specific cognitions) are more easily assessed by within-day sampling schedules at a high frequency, while events that typically persist over several hours or days typically require a lower frequency of assessment.

Missing data are another important methodologic issue, but it was not consistently reported across studies. Most participants with $\mathrm{BD}$ are highly compliant with the multiple within-day assessments of EMA studies, with an average cross- study compliance rate of $85.9 \%$ (range: $78-90.5 \%$ ) and that do not differ considerably from those of controls (average: $85.3 \%$; range $83-87 \%)$. Again, due to the continuous nature of passive monitoring, missing data are rarely reported because it may be erroneously assumed that such information is not pertinent. In our review, only one study published information on missing data, restricting it to stating the percent of subjects who wore their monitors for the entirety of the study [63]. Whether this lack of reporting is because of excellent general adherence across studies, or due to study conventions or other reasons is unknown. However, this lack of clarity underscores the need to systematically report this information in future studies.

A number of techniques to enhance compliance and reduce missing data in people with $\mathrm{BD}$ and other serious mental disorders including people with schizophrenia. These approaches generally include three strategies: (1) participation-contingent compensation (whereby bonuses are provided based on the achievement of a specified threshold of compliance; it is used for both active and passive assessments); (2) Device-based restitution of compliance information (such as providing a counter for the percentage of completed assessments; it is used in EMA studies); and (3) providing information to the participant to encourage their participation as well as reminder contacts throughout the assessment period (both active and passive assessments). This third approach is rarely mentioned when presenting study methods, but it is perhaps the most important of all established strategies. In brief, compliance can be greatly improved by communicating the value of unique individual-level information to the participant at study inception and explaining how it supplements other information that is inaccessible to other research methods.

\section{SUMMARY AND FUTURE DIRECTIONS}

\section{Summary}

Rapidly accumulating data from mobile assessments of people with mental disorders is facilitating our ability to track the patterns of core emotions, behaviors, biologic rhythms, and their contextual influences in real time. These approaches have been widely applied to study the core features, traits, changes in states, and impact of treatments in BD [61]. The dozens of published studies that have used actigraphy in $\mathrm{BD}$ converge in showing significantly greater average variability of total sleep time and sleep disturbances among those with this disorder compared to controls. There is also compelling evidence for lower average motor activity among people with BD from studies of actigraphy in the euthymic state as well as during depressive episodes. These studies have shown that people with BD have a later sleep midpoint, a marker of morningness-eveningness, and a shift to activity later in the day than those with MDD or controls.

Despite the consistency of the findings, there is still insufficient evidence regarding state versus trait effects, differences by subtypes of BD (including BDI vs BDII) and the lack of specificity of findings on sleep patterns for BD. These rich studies have nonetheless provided high-resolution phenotyping of people with $\mathrm{BD}$ and other conditions in real time, but they are time and laborintensive, requiring a fairly long-term investment of investigators and participants. Perhaps for this reason, sample sizes in most of these studies are generally too modest to explore correlates of domains jointly assessed by active and passive monitoring such as confounding influence of social structure (weekend vs weekday), seasonality, substances or medications, and physical conditions that frequently co-occur with BD. Non-systematic samples have often precluded exploration of sex and age effects, a finding that is particularly noteworthy given the growing evidence for both age and sex differences in the biologic and contextual factors influencing mood, sleep, motor activity, and circadian rhythms. Nevertheless, despite limitations of the current evidence base, mobile technologies will continue to provide an increasingly powerful tool to identify the heterogeneity of BD and its biologic and environmental correlates.

This review also shows the progress in the shift toward the conceptualization of dysregulation of rhythms in BD as opposed to the accumulation of symptoms of sleep, energy, appetite, and activity. Whereas most actigraphy research on BD has focused on sleep patterns, the more recent shift to characterize motor activity as a core feature of this condition has facilitated a more accurate description of the full 24-h cycle. Circadian rhythms that were often not incorporated in early work, are now being recognized as sources of heterogeneity for the genetic, biologic, and contextual factors that contribute to BD. Advances in our understanding of the complex molecular biology of circadian rhythms and their intrinsic and extrinsic drivers [107] will guide the development of more systematic hypotheses regarding specific components of $\mathrm{BD}$ that can be tested using real-time technology over longer periods in the natural contexts of daily life.

\section{Clinical implications}

There have been several efforts to incorporate actigraphy as an objective measure to assess the impact of treatment [61, 108]. For example, Hwang et al. [109] used actigraphy to examine differential treatment effects of quetiapine and lithium for BD. Several studies are now using mobile tools to provide objective measures of changes in sleep, and there is a growing effort to use mobile tools to actually deliver treatment for the improvement of sleep regularity and related rhythms [110]. These mobile tools may 
also be valuable in characterizing symptoms and progression in order to provide a more accurate diagnosis by discriminating between $\mathrm{BD}$ and ADHD [14] or borderline personality disorder and BD [63]. As suggested by Benard et al. [108], a further important application of these mobile tools is to identify the role of sleep and circadian rhythms in suicide attempts. By establishing stable dynamic patterns of multiple systems in tandem over relatively long periods, it may be possible to track people at risk for suicide ideation and attempts that are one of the most tragic consequences of $\mathrm{BD}$.

Aside from activity, sleep, and circadian parameters, the rapid developments in multimodal sensors that can be used to collect physiologic parameters such as melatonin, cortisol, heart rate, skin temperature, and conductance, and light spectrum and intensity have provided a more comprehensive depiction of the spectrum of circadian systems in real time. However, understanding of the biologic systems underlying domains tracked by passive assessments, such as circadian sensors and actigraphy, is limited by inferences regarding concomitant subjective emotional states, such as anxiety, irritability, and rapidly fluctuating cognitive states (e.g., inattention, executive dysfunction) that are core features of $\mathrm{BD}$. The collection of patient self-reports or in vivo performance on mobile cognitive tests, through EMA [36] also represents an advance over more static neuropsychological testing. When coupled with active monitoring of psychological states, behavior, cognition, and social and contextual factors, these measures are enabling a revolution in neuropsychiatric monitoring than can provide a comprehensive portrait of emotions, behavior, and their underlying physiologic parameters. In a recent review of these tools, Reinertsen and Clifford [99] describe how the growing availability of contextual and physiologically relevant digital sensors could help address the challenges of lack of access to care and artificial clinical settings that may enable objective indexing of patient severity, and inform rapid adjustment of treatment in real time.

\section{Future directions}

The use of mobile technologies provides exciting opportunities to address the mind-body dichotomy that has long been central to our understanding of human behavior and psychopathology. This review summarized information on $\mathrm{BD}$ based on tools that passively assess essential biological or physical processes such as sleep, activity and other rhythmic functions, as well as research that has actively gathered data to track the subjective experiences that are inaccessible to tools for objective data collection. These tools provide information on different aspects of experience, so the combination of these approaches is likely to be increasingly frequent in psychiatric research in the coming decade.

The strong associations that were observed both within and between the three major domains of sleep, physical activity, and circadian rhythms derived from the features of actigraphy highlight the need to study these systems simultaneously. The duration of actigraphy and EMA in most studies of BD has generally averaged one or two weeks that provides only a brief snapshot of the dynamic cross-domain interrelations that may not generalize over longer time periods. As these tools have become more refined and available, however, it is now possible to administer real-time assessments over longer periods that can be used to characterize clinical states, monitor treatment, and identify the influence of environmental conditions, such as light, temperature, and seasons, that may have a broad influence on rhythms and reactivity. One cautionary note is that the striking increase in the number of mobile apps for BD as well as for other psychiatric symptoms or disorders, often lacking an evidence base, has made it challenging for patients and clinicians alike to select appropriate devices and programs. There is therefore an urgent need for the establishment of standards for their use in description, prediction, and treatment because few of these apps adhere to contemporary practice guidelines lines or standards $[26,27]$

The developmental nature of changes in sleep, circadian rhythms, and motor activity that has been shown in studies of humans and in basic science requires further investigation. Several studies of the offspring of parents with BD show that at-risk youth may already manifest sleep problems and variability in daily rhythms of sleep and physical activity [111, 112]. Therefore, sleep difficulties and unstable circadian rhythms could comprise endophenotypes or predisposing factors for BD. Future prospective studies of offspring at risk or of people with early manifestation of suspected BD will be valuable in identifying specific biomarkers for BD.

One particularly exciting future direction is the opportunity to study the influence of light on sleep, motor activity, and circadian function in real time. As reviewed above, although the influence of light on BD has long been suspected and used as a treatment to regulate the rhythms of people with this disorder, its neural architecture has only recently been articulated. In particular, advances in characterizing the retinal pathways affected by light and depression-like behavior and cognition in basic science research provides a powerful opportunity to track these same systems in humans. This work could inform studies have used actigraphy to track the effects of blue-light-blocking glasses and/ or other manipulations of light exposure as a tool to modify rhythms in people with BD [113].

Despite clear points of consensus in research findings and the promise of new technological developments for the future, there is a pressing need for greater coordination across studies employing these mobile approaches in order to standardize the procedures, analytic methods and study the factors that influence circadian rhythms in BD. The following recommendations are therefore formulated in order to improve compatibility across studies and advance scientific contributions to the field:

1. These findings strongly support the importance of combining both objective and subjective assessments to link personal experience and contextual influences to objectively rated physiologic and behavioral domains. The growing availability of multimodal tools for both active and passive will facilitate our understanding of the crossregulation of multiple systems as well as their directional links that can enhance understanding of etiology. Therefore, expanding this work to include a broader series of domains that are related to the complex web of systems involved in BD will inform potential etiologic chains that could be used to identify targets for intervention.

2. Now that there are fairly consistent findings across more than two dozen studies of actigraphy and EMA in people with $\mathrm{BD}$, there is a need to develop a deeper understanding of how these findings may differ across development, sex, age, and ethnicity. It will also be important to gain understanding of the influence of medications, smoking, and alcohol use on these activities, sleep, and circadian parameters, as well as insight into the increased level of BMI in $\mathrm{BD}$ that is also strongly related to many of the parameters derived from actigraphy. Likewise, studies of ethnic differences in mood disorders and these related systems will require a concerted effort to obtain more diverse samples.

3. One of the most important gaps was the variability of clinical assessment methods to accompany actigraphy and the specific symptoms that were assessed in EMA studies. Developing common protocols for the collection of diagnostic and other clinical data could enhance the comparability of this work. These protocols should include methods to track the subthreshold expression of BD, incorporate comorbid conditions that were rarely 
considered in the above studies, and contextual influences on their manifestations over time. Finally, the lack of specificity that has been apparent in many of the studies also highlights the need to move beyond studies of a single case group to multiple subgroups to further investigate differences across the diagnostic spectrum.

4. Most of the reviewed studies were limited to less than four weeks. Expansion of this work to elucidate patterns at different times of the year that would provide insight into the stability of these findings is a critical next step in this work. As mobile tools, particularly passive assessments, become more refined and less burdensome, it will be possible to collect data over longer periods of time that can provide information on the stability of the findings across time, season, and life changes.

Collaborative efforts that develop common protocols can facilitate cross-study comparisons and cross-site aggregation. There are several large-scale ongoing studies that are using a common protocol for mobile tools to track treatment and progression of BD [114] and major depression [16]. By accumulating larger sample sizes, such studies will help to address limitations in power to pursue mechanistic studies that have not been possible in smaller samples. Our groups at the NIMH and Johns Hopkins Bloomberg School of Public Health have established a collaborative research network, the Motor Activity Research Consortium for Health (mMARCH) to facilitate the coordination of procedures, analyses, and data sharing among research groups around collecting actigraphy and EMA data focused on mood disorders (ZIA MH002954-04 Motor Activity Research Consortium for Health (mMARCH)). Such initiatives should greatly reduce the cross-site heterogeneity that has hindered the aggregation of data and prevented high-powered, multi-site analyses of questions of essential importance to BD as well as to other forms of mental illness.

\section{FUNDING AND DISCLOSURE}

This research was supported by the Intramural Research Program of the National Institute of Mental Health through grant ZIA MH002954-02 [Motor Activity Research Consortium for Health (mMarch)]. All authors have nothing to disclose.

\section{DISCLAIMER}

The views and opinions expressed in this article are those of the authors and should not be construed to represent the views of any of the sponsoring organizations, agencies, or the US government. This study was determined not human subjects research by the NIH Office of IRB Operations.

\section{ACKNOWLEDGEMENTS}

The funding organizations had no role in the design and conduct of the study collection, management, analysis, and interpretation of the data; preparation, review, or approval of the paper; and decision to submit the paper for publication.

\section{AUTHOR CONTRIBUTIONS}

Drs. GD, JS, and KRM all contributed to the drafting and revision of the paper. All authors critically revised the paper for important intellectual content and approved the final version.

\section{ADDITIONAL INFORMATION}

Publisher's note Springer Nature remains neutral with regard to jurisdictional claims in published maps and institutional affiliations.

\section{REFERENCES}

1. Denicoff KD, Ali SO, Sollinger AB, Smith-Jackson EE, Leverich GS, Post RM. Utility of the daily prospective National Institute of Mental Health Life-Chart Method (NIMH-LCM-p) ratings in clinical trials of bipolar disorder. Depress Anxiety. 2002;15:1-9. https://doi.org/10.1002/da.1078.

2. Post RM, Denicoff KD, Leverich GS, Altshuler LL, Frye MA, Suppes TM, et al. Morbidity in 258 bipolar outpatients followed for 1 year with daily prospective ratings on the NIMH life chart method. J Clin Psychiatry. 2003;64:680-90. https:// doi.org/10.4088/jcp.v64n0610. quiz 738-9.

3. Meyer N, Faulkner SM, McCutcheon RA, Pillinger T, Dijk DJ, MacCabe JH. Sleep and circadian rhythm disturbance in remitted schizophrenia and bipolar disorder: a systematic review and meta-analysis. Schizophr Bull. 2020. https://doi. org/10.1093/schbul/sbaa024.

4. Bauer M, Glenn T, Whybrow PC, Grof P, Rasgon N, Alda M, et al. Changes in selfreported sleep duration predict mood changes in bipolar disorder. Psychol Med. 2008;38:1069-71. https://doi.org/10.1017/S0033291708003280.

5. Plante DT, Winkelman JW. Sleep disturbance in bipolar disorder: therapeutic implications. Am J Psychiatry. 2008;165:830-43. https://doi.org/10.1176/appi. ajp.2008.08010077.

6. Lockley SW, Skene DJ, Arendt J. Comparison between subjective and actigraphic measurement of sleep and sleep rhythms. J Sleep Res. 1999;8:175-83. https:// doi.org/10.1046/j.1365-2869.1999.00155.x.

7. Ancoli-Israel S, Martin JL, Blackwell T, Buenaver L, Liu L, Meltzer LJ, et al. The SBSM guide to actigraphy monitoring: clinical and research applications. Behav Sleep Med. 2015;13:S4-S38.

8. Smith CS, Reilly C, Midkiff K. Evaluation of three circadian rhythm questionnaires with suggestions for an improved measure of morningness. J Appl Psychol. 1989;74:728-38. https://doi.org/10.1037/0021-9010.74.5.728.

9. Scott J, Murray G, Henry C, Morken G, Scott E, Angst J, et al. Activation in bipolar disorders: a systematic review. JAMA Psychiatry. 2017;74:189-96. https://doi.org/ 10.1001/jamapsychiatry.2016.3459.

10. De Crescenzo F, Economou A, Sharpley AL, Gormez A, Quested DJ. Actigraphic features of bipolar disorder: a systematic review and meta-analysis. Sleep Med Rev. 2017;33:58-69. https://doi.org/10.1016/j.smrv.2016.05.003.

11. Wee ZY, Yong SWL, Chew QH, Guan C, Lee TS, Sim K. Actigraphy studies and clinical and biobehavioural correlates in schizophrenia: a systematic review. J Neural Transm. 2019;126:531-58. https://doi.org/10.1007/s00702-019-01993-2.

12. Zipunnikov V, Caffo B, ousem DM, Davatzikos C, Schwartz BS, Crainiceanu C. Multilevel functional principal component analysis for high-dimensional data. J Comput Graph Stat. 2011;20:852-73.

13. Bertz JW, Epstein DH, Reamer D, Kowalczyk WJ, Phillips KA, Kennedy AP, et al. Sleep reductions associated with illicit opioid use and clinic-hour changes during opioid agonist treatment for opioid dependence: measurement by electronic diary and actigraphy. J Subst Abus Treat. 2019;106:43-57. https://doi. org/10.1016/j.jsat.2019.08.011.

14. Faedda GL, Ohashi K, Hernandez M, McGreenery CE, Grant MC, Baroni A, et al. Actigraph measures discriminate pediatric bipolar disorder from attention-deficit/hyperactivity disorder and typically developing controls. J Child Psychol Psychiatry. 2016;57:706-16. https://doi.org/10.1111/jcpp.12520.

15. Doherty A, Jackson D, Hammerla N, Plotz T, Olivier P, Granat MH, et al. Large scale population assessment of physical activity using wrist worn accelerometers: The UK Biobank Study. PLoS ONE. 2017;12:e0169649. https://doi.org/ 10.1371/journal.pone.0169649.

16. Matcham F, Barattieri di San Pietro C, Bulgari V, de Girolamo G, Dobson R Eriksson $\mathrm{H}$, et al. Remote assessment of disease and relapse in major depressive disorder (RADAR-MDD): a multi-centre prospective cohort study protocol. BMC Psychiatry. 2019;19:72. https://doi.org/10.1111/jcpp.12520.

17. Leroux A, Di J, Smirnova E, McGuffey EJ, Cao Q, Bayatmokhtari E, et al. Organizing and analyzing the activity data in NHANES. Stat Biosci. 2019;11:262-87. https://doi.org/10.1249/mss.0000000000000778.

18. Bagot KS, Matthews SA, Mason M, Squeglia LM, Fowler J, Gray K, et al. Current, future and potential use of mobile and wearable technologies and social media data in the $A B C D$ study to increase understanding of contributors to child health. Dev Cogn Neurosci. 2018;32:121-9. https://doi.org/10.1016/j. dcn.2018.03.008.

19. Guidi A, Salvi S, Ottaviano M, Gentili C, Bertschy G, de Rossi D, et al. Smartphone application for the analysis of prosodic features in running speech with a focus on bipolar disorders: system performance evaluation and case study. Sensors 2015;15:28070-87. https://doi.org/10.3390/s151128070.

20. Karam ZN, Provost EM, Singh S, Montgomery J, Archer C, Harrington G, et al. Ecologically valid long-term mood monitoring of individuals with bipolar disorder using speech. Proc IEEE Int Conf Acoust Speech Signal Process. 2014;2014:4858-62. https://doi.org/10.1109/ICASSP.2014.6854525. 
21. Torous J, Summergrad P, Nassir, Ghaemi S. Bipolar disorder in the digital age: new tools for the same illness. Int J Bipolar Disord. 2016;4:25. https://doi.org/ 10.1186/s40345-016-0065-1.

22. Torous J, Brady R. Advancing care for bipolar disorder today and breakthroughs in access and treatments tomorrow with mobile health and smartphone apps. Bipolar Disord. 2020;22:211-2. https://doi.org/10.1111/bdi.12928.

23. Gliddon E, Barnes SJ, Murray G, Michalak EE. Online and mobile technologies for self-management in bipolar disorder: a systematic review. Psychiatr Rehabil J. 2017;40:309-19. https://doi.org/10.1037/prj0000270.

24. Faurholt-Jepsen M, Vinberg M, Frost M, Christensen EM, Bardram JE, Kessing LV. Smartphone data as an electronic biomarker of illness activity in bipolar disorder. Bipolar Disord. 2015;17:715-28. https://doi.org/10.1111/bdi.12332.

25. Faurholt-Jepsen M, Frost M, Ritz C, Christensen EM, Jacoby AS, Mikkelsen RL, et al. Daily electronic self-monitoring in bipolar disorder using smartphones the MONARCA I trial: a randomized, placebo-controlled, single-blind, parallel group trial. Psychol Med. 2015;45:2691-704. https://doi.org/10.1017/ S0033291715000410.

26. Seppala J, De Vita I, Jamsa T, Miettunen J, Isohanni M, Rubinstein K, et al. Mobile phone and wearable sensor-based mhealth approaches for psychiatric disorders and symptoms: systematic review. JMIR Ment Health. 2019;6:e9819. https://doi. org/10.2196/mental.9819.

27. Nicholas J, Larsen ME, Proudfoot J, Christensen H. Mobile apps for bipolar disorder: a systematic review of features and content quality. J Med Internet Res. 2015;17:e198 https://doi.org/10.2196/jmir.4581.

28. Merikangas KR, Swendsen J, Hickie IB, Cui L, Shou H, Merikangas AK, et al. Realtime mobile monitoring of the dynamic associations among motor activity, energy, mood, and sleep in adults with bipolar disorder. JAMA Psychiatry. 2019;76:190-8. https://doi.org/10.1001/jamapsychiatry.2018.3546.

29. Johnson E, Grondin O, Barrault M, M. F, Helbig S, M. H, et al. Computerized ambulatory monitoring in psychiatry: a multi-site collaborative study of acceptability, compliance, and reactivity. Int Jourmal Methods Psychiatry Res. 2009;18:48-57.

30. Granholm E, Loh C, Swendsen J. Feasibility and validity of computerized ecological momentary assessment in schizophrenia. Schizophr Bull. 2008;34:507-14.

31. Johnson El, Barrault M, Nadeau L, Swendsen J, Trull TJ, Solhan MB, et al. Feasibility and validity of computerized ambulatory monitoring in drug-dependent women. Drug Alcohol Depend. 2009;99:322-6. https://doi.org/10.1093/schbul/ sbm113.

32. Husky MM, Gindre C, Mazure CM, Brebant C, Nolen-Hoeksema S, Sanacora G, et al. Computerized ambulatory monitoring in mood disorders: feasibility, compliance, and reactivity. Psychiatry Res. 2010;178:440-2. https://doi.org/ 10.1016/j.psychres.2010.04.045.

33. Lemey C, Larsen ME, Devylder J, Courtet $P$, Billot R, Lenca $P$, et al. Clinicians' concerns about mobile ecological momentary assessment tools designed for emerging psychiatric problems: prospective acceptability assessment of the MEmind app. J Med Internet Res. 2019;21:e10111. https://doi.org/10.1016/j. drugalcdep.2018.03.016

34. Mackesy-Amiti ME, Boodram B. Feasibility of ecological momentary assessment to study mood and risk behavior among young people who inject drugs. Drug Alcohol Depend. 2018;187:227-35. https://doi.org/10.2196/jmir.7602.

35. Johnson El, Sibon I, Renou P, Rouanet F, Allard M, Swendsen J, et al. Feasibility and validity of computerized ambulatory monitoring in stroke patients. Neurology. 2009;73:1579-83. https://doi.org/10.1016/j.jagp.2016.11.019.

36. Moore RC, Kaufmann CN, Rooney AS, Moore DJ, Eyler LT, Granholm E, et al. Feasibility and acceptability of ecological momentary assessment of daily functioning among older adults with HIV. Am J Geriatr Psychiatry. 2017;25:829-40.

37. Solk P, Gavin K, Fanning J, Welch W, Lloyd G, Cottrell A, et al. Feasibility and acceptability of intensive longitudinal data collection of activity and patientreported outcomes during chemotherapy for breast cancer. Qual Life Res. 2019;28:3333-46. https://doi.org/10.1089/dia.2018.0064.

38. Mulvaney SA, Vaala S, Hood KK, Lybarger C, Carroll R, Williams L, et al. Mobile momentary assessment and biobehavioral feedback for adolescents with type 1 diabetes: feasibility and engagement patterns. Diabetes Technol Ther. 2018;20:465-74. https://doi.org/10.1089/dia.2018.0064.

39. Knell G, Gabriel KP, Businelle MS, Shuval K, Wetter DW, Kendzor DE. Ecological momentary assessment of physical activity: validation study. J Med Internet Res. 2017;19:e253.

40. Gunn PJ, Middleton B, Davies SK, Revell VL, Skene DJ. Sex differences in the circadian profiles of melatonin and cortisol in plasma and urine matrices under constant routine conditions. Chronobiol Int. 2016;33:39-50. https://doi.org/ 10.3109/07420528.2015.1112396.
41. Carrier J, Semba K, Deurveilher S, Drogos L, Cyr-Cronier J, Lord C, et al. Sex differences in age-related changes in the sleep-wake cycle. Front Neuroendocrinol. 2017;47:66-85. https://doi.org/10.1016/j.yfrne.2017.07.004.

42. Nicolaides NC, Charmandari E, Kino T, Chrousos GP. Stress-related and circadian secretion and target tissue actions of glucocorticoids: impact on health. Front Endocrinol (Lausanne). 2017;8:70. https://doi.org/10.3389/fendo.2017.00070.

43. Lewy AJ, Wehr TA, Goodwin FK, Newsome DA, Rosenthal NE. Manic-depressive patients may be supersensitive to light. Lancet. 1981;1:383-4. https://doi.org/ 10.1016/s0140-6736(81)91697-4.

44. Lewy AJ, Nurnberger JI Jr, Wehr TA, Pack D, Becker LE, Powell RL, et al. Supersensitivity to light: possible trait marker for manic-depressive illness. Am J Psychiatry. 1985;142:725-7. https://doi.org/10.1176/ajp.142.6.725.

45. Hallam KT, Olver JS, Norman TR. Effect of sodium valproate on nocturnal melatonin sensitivity to light in healthy volunteers. Neuropsychopharmacology. 2005;30:1400-4. https://doi.org/10.1038/sj.npp.1300739.

46. Hallam KT, Olver JS, Horgan JE, McGrath C, Norman TR. Low doses of lithium carbonate reduce melatonin light sensitivity in healthy volunteers. Int J Neuropsychopharmacol. 2005;8:255-9. https://doi.org/10.1017/S1461145704004894.

47. Wirz-Justice A, Reme C, Prunte A, Heinen U, Graw P, Urner U. Lithium decreases retinal sensitivity, but this is not cumulative with years of treatment. Biol Psychiatry. 1997;41:743-6. https://doi.org/10.1016/S0006-3223(97)00001-2.

48. Abe M, Herzog ED, Block GD. Lithium lengthens the circadian period of individual suprachiasmatic nucleus neurons. Neuroreport. 2000;11:3261-4. https:// doi.org/10.1097/00001756-200009280-00042.

49. Abreu T, Braganca M. The bipolarity of light and dark: a review on bipolar disorder and circadian cycles. J Affect Disord. 2015;185:219-29. https://doi.org/ 10.1016/j.jad.2015.07.017.

50. Novakova M, Prasko J, Latalova K, Sladek M, Sumova A. The circadian system of patients with bipolar disorder differs in episodes of mania and depression. Bipolar Disord. 2015;17:303-14. https://doi.org/10.1111/bdi.12270.

51. Esaki Y, Obayashi K, Saeki K, Fujita K, Iwata N, Kitajima T. Association between light exposure at night and manic symptoms in bipolar disorder: cross-sectional analysis of the APPLE cohort. Chronobiol Int. 2020:1-10. https://doi.org/10.1080/ 07420528.2020.1746799.

52. Paksarian D, Rudolph KE, Stapp EK, Dunster GP, He J, Mennitt D, et al. Association of outdoor artificial light at night with mental disorders and sleep patterns among US adolescents. JAMA Psychiatry. 2020. https://doi.org/10.1001/ jamapsychiatry.2020.1935.

53. Robillard R, Naismith SL, Rogers NL, Scott EM, Ip TK, Hermens DF, et al. Sleepwake cycle and melatonin rhythms in adolescents and young adults with mood disorders: comparison of unipolar and bipolar phenotypes. Eur Psychiatry. 2013;28:412-6. https://doi.org/10.1016/j.eurpsy.2013.04.001.

54. Dallaspezia S, Benedetti FMelatonin. circadian rhythms, and the clock genes in bipolar disorder. Curr Psychiatry Rep. 2009;11:488-93. https://doi.org/10.1007/ s11920-009-0074-1.

55. Nurnberger JI Jr, Adkins S, Lahiri DK, Mayeda A, Hu K, Lewy A, et al. Melatonin suppression by light in euthymic bipolar and unipolar patients. Arch Gen Psychiatry. 2000;57:572-9. https://doi.org/10.1001/archpsyc.57.6.572.

56. Lewy AJ. Circadian misalignment in mood disturbances. Curr Psychiatry Rep. 2009;11:459-65. https://doi.org/10.1007/s11920-009-0070-5.

57. Havermans R, Nicolson NA, Berkhof J, deVries MW. Patterns of salivary cortisol secretion and responses to daily events in patients with remitted bipolar disorder. Psychoneuroendocrinology. 2011;36:258-65. https://doi.org/10.1016/j. psyneuen.2010.07.016.

58. Nikitopoulou G, Crammer JL. Change in diurnal temperature rhythm in manicdepressive illness. $\mathrm{Br}$ Med J. 1976;1:1311-4. https://doi.org/10.1136/ bmj.1.6021.1311.

59. Carr O, Saunders KEA, Bilderbeck AC, Tsanas A, Palmius N, Geddes JR, et al. Desynchronization of diurnal rhythms in bipolar disorder and borderline personality disorder. Transl Psychiatry. 2018;8:79 https://doi.org/10.1038/s41398018-0125-7.

60. Murray G, Gottlieb J, Hidalgo MP, Etain B, Ritter P, Skene DJ, et al. Measuring circadian function in bipolar disorders: empirical and conceptual review of physiological, actigraphic, and self-report approaches. Bipolar Disord. 2020. https://doi.org/10.1111/bdi.12963.

61. Tazawa Y, Wada M, Mitsukura Y, Takamiya A, Kitazawa M, Yoshimura M, et al. Actigraphy for evaluation of mood disorders: a systematic review and metaanalysis. J Affect Disord. 2019;253:257-69. https://doi.org/10.1016/j. jad.2019.04.087.

62. Carr O, Saunders KEA, Tsanas A, Bilderbeck AC, Palmius N, Geddes JR, et al. Variability in phase and amplitude of diurnal rhythms is related to variation of mood in bipolar and borderline personality disorder. Sci Rep. 2018;8:1649. https://doi.org/10.1038/s41598-018-19888-9. 
63. McGowan NM, Goodwin GM, Bilderbeck AC, Saunders KEA. Circadian restactivity patterns in bipolar disorder and borderline personality disorder. Transl Psychiatry. 2019;9:195. https://doi.org/10.1038/s41398-019-0526-2.

64. Shou H, Cui L, Hickie I, Lameira D, Lamers F, Zhang J, et al. Dysregulation of objectively assessed 24-hour motor activity patterns as a potential marker for bipolar I disorder: results of a community-based family study. Transl Psychiatry. 2017;7:e1211. https://doi.org/10.1038/tp.2017.136.

65. Slyepchenko A, Allega OR, Leng X, Minuzzi L, Eltayebani MM, Skelly M, et al. Association of functioning and quality of life with objective and subjective measures of sleep and biological rhythms in major depressive and bipolar disorder. Aust N. Z J Psychiatry. 2019;53:683-96. https://doi.org/10.1177/ 0004867419829228.

66. Gold AK, Sylvia LG. The role of sleep in bipolar disorder. Nat Sci Sleep 2016;8:207-14. https://doi.org/10.2147/NSS.S85754.

67. Levenson J, Frank E. Sleep and circadian rhythm abnormalities in the pathophysiology of bipolar disorder. Curr Top Behav Neurosci. 2011;5:247-62. https:// doi.org/10.1007/7854_2010 50.

68. Pandi-Perumal SR, Moscovitch A, Srinivasan V, Spence DW, Cardinali DP, Brown GM. Bidirectional communication between sleep and circadian rhythms and its implications for depression: lessons from agomelatine. Prog Neurobiol. 2009;88:264-71. https://doi.org/10.1016/j.pneurobio.2009.04.007.

69. Wehr TA, Turner EH, Shimada JM, Lowe $\mathrm{CH}$, Barker C, Leibenluft E. Treatment of rapidly cycling bipolar patient by using extended bed rest and darkness to stabilize the timing and duration of sleep. Biol Psychiatry. 1998;43:822-8. https://doi.org/10.1016/s0006-3223(97)00542-8.

70. Ritter PS, Marx C, Bauer M, Leopold K, Pfennig A. The role of disturbed sleep in the early recognition of bipolar disorder: a systematic review. Bipolar Disord. 2011;13:227-37. https://doi.org/10.1111/j.1399-5618.2011.00917.x.

71. Vancampfort D, Firth J, Schuch F, Rosenbaum S, De Hert M, Mugisha J, et al. Physical activity and sedentary behavior in people with bipolar disorder: a systematic review and meta-analysis. J Affect Disord. 2016;201:145-52. https:// doi.org/10.1016/j.jad.2016.05.020.

72. Varma VR, Dey D, Leroux A, Di J, Urbanek J, Xiao L, et al. Re-evaluating the effect of age on physical activity over the lifespan. Prev Med. 2017;101:102-8. https:// doi.org/10.1016/j.ypmed.2017.05.030.

73. Horne JA, Ostberg O. A self-assessment questionnaire to determine morningnesseveningness in human circadian rhythms. Int J Chronobiol. 1976;4:97-110.

74. Roenneberg T, Wirz-Justice A, Merrow M. Life between clocks: daily temporal patterns of human chronotypes. J Biol Rhythms. 2003;18:80-90. https://doi.org/ $10.1177 / 0748730402239679$.

75. Gershon A, Kaufmann CN, Depp CA, Miller S, Do D, Zeitzer JM, et al. Subjective versus objective evening chronotypes in bipolar disorder. J Affect Disord. 2018;225:342-9. https://doi.org/10.1016/j.jad.2017.08.055.

76. Melo MCA, Abreu RLC, Linhares Neto VB, de Bruin PFC, de Bruin VMS. Chronotype and circadian rhythm in bipolar disorder: a systematic review. Sleep Med Rev. 2017:34:46-58. https://doi.org/10.1016/j.smrv.2016.06.007.

77. Fischer D, Lombardi DA, Marucci-Wellman H, Roenneberg T. Chronotypes in the US-influence of age and sex. PLoS ONE. 2017;12:e0178782. https://doi.org/ 10.1371/journal.pone.0178782.

78. Geoffroy PA, Scott J, Boudebesse C, Lajnef M, Henry C, Leboyer M, et al. Sleep in patients with remitted bipolar disorders: a meta-analysis of actigraphy studies. Acta Psychiatr Scand. 2015;131:89-99. https://doi.org/10.1111/acps.12367.

79. Gonzalez R, Suppes T, Zeitzer J, McClung C, Tamminga C, Tohen M, et al. The association between mood state and chronobiological characteristics in bipolar I disorder: a naturalistic, variable cluster analysis-based study. Int J Bipolar Disord. 2018;6:5. https://doi.org/10.1186/s40345-017-0113-5.

80. Krane-Gartiser K, Steinan MK, Langsrud K, Vestvik V, Sand T, Fasmer OB, et al. Mood and motor activity in euthymic bipolar disorder with sleep disturbance. $J$ Affect Disord. 2016;202:23-31. https://doi.org/10.1016/j.jad.2016.05.012.

81. Krane-Gartiser K, Henriksen TEG, Morken G, Vaaler AE, Fasmer OB. Motor activity patterns in acute schizophrenia and other psychotic disorders can be differentiated from bipolar mania and unipolar depression. Psychiatry Res. 2018;270:418-25. https://doi.org/10.1016/j.psychres.2018.10.004.

82. Pagani L, St Clair PA, Teshiba TM, Service SK, Fears SC, Araya C, et al. Genetic contributions to circadian activity rhythm and sleep pattern phenotypes in pedigrees segregating for severe bipolar disorder. Proc Natl Acad Sci USA 2016;113:E754-61. https://doi.org/10.1073/pnas.1513525113.

83. Sebela A, Novak T, Kemlink D, Goetz M. Sleep characteristics in child and adolescent offspring of parents with bipolar disorder: a case control study. BMC Psychiatry. 2017;17:199. https://doi.org/10.1186/s12888-017-1361-8.

84. Gehrman PR, Ghorai A, Goodman M, McCluskey R, Barilla H, Almasy L, et al. Twin-based heritability of actimetry traits. Genes Brain Behav. 2019;18:e12569 https://doi.org/10.1111/gbb.12569.
85. aan het Rot M, Hogenelst K, Schoevers RA. Mood disorders in everyday life: a systematic review of experience sampling and ecological momentary assessment studies. Clin Psychol Rev. 2012;32:510-23. https://doi.org/10.1016/j. cpr.2012.05.007.

86. Malik A, Goodwin GM, Holmes EA. Contemporary approaches to frequent mood monitoring in bipolar disorder. J Exp Psychopathol. 2012;3:572-81. https://doi. org/10.5127/jep.014311.

87. Ebner-Priemer UW, Trull TJ. Ecological momentary assessment of mood disorders and mood dysregulation. Psychol Assess. 2009;21:463-75. https://doi. org/10.1037/a0017075.

88. Trull TJ, Ebner-Priemer UW. Using experience sampling methods/ecological momentary assessment (ESM/EMA) in clinical assessment and clinical research: introduction to the special section. Psychol Assess. 2009;21:457-62. https://doi. org/10.1037/a0017653.

89. Husky M, Olie E, Guillaume S, Genty C, Swendsen J, Courtet P. Feasibility and validity of ecological momentary assessment in the investigation of suicide risk. Psychiatry Res. 2014;220:564-70. https://doi.org/10.1016/j.psychres.2014.08.019.

90. Serre F, Fatseas M, Debrabant R, Alexandre JM, Auriacombe M, Swendsen J, et al. Ecological momentary assessment in alcohol, tobacco, cannabis and opiate dependence: a comparison of feasibility and validity. Drug Alcohol Depend 2012;126:118-23. https://doi.org/10.1002/da.22949.

91. Knowles R, Tai S, Jones SH, Highfield J, Morriss R, Bentall RP. Stability of selfesteem in bipolar disorder: comparisons among remitted bipolar patients, remitted unipolar patients and healthy controls. Bipolar Disord. 2007;9:490-5. https://doi.org/10.1111/j.1399-5618.2007.00457.x.

92. Havermans R, Nicolson NA, Berkhof J, deVries MW. Mood reactivity to daily events in patients with remitted bipolar disorder. Psychiatry Res. 2010;179:47-52. https://doi.org/10.1016/j.psychres.2009.10.020.

93. Havermans R, Nicolson NA, Devries MW. Daily hassles, uplifts, and time use in individuals with bipolar disorder in remission. J Nerv Ment Dis. 2007;195:745-51. https://doi.org/10.1097/NMD.0b013e318142cbf0.

94. Schwartz S, Schultz S, Reider A, Saunders EF. Daily mood monitoring of symptoms using smartphones in bipolar disorder: a pilot study assessing the feasibility of ecological momentary assessment. J Affect Disord. 2016;191:88-93. https://doi.org/10.1016/j.jad.2015.11.013.

95. Axelson DA, Bertocci MA, Lewin DS, Trubnick LS, Birmaher B, Williamson DE, et al. Measuring mood and complex behavior in natural environments: use of ecological momentary assessment in pediatric affective disorders. J Child Adolesc Psychopharmacol. 2003;13:253-66. https://doi.org/10.1089/ 104454603322572589.

96. Myin-Germeys I, Peeters F, Havermans R, Nicolson NA, DeVries MW, Delespaul P, et al. Emotional reactivity to daily life stress in psychosis and affective disorder: an experience sampling study. Acta Psychiatr Scand. 2003;107:124-31. https:// doi.org/10.1034/j.1600-0447.2003.02025.x.

97. Lamers F, Swendsen J, Cui L, Husky M, Johns J, Zipunnikov V, et al. Mood reactivity and affective dynamics in mood and anxiety disorders. J Abnorm Psychol. 2018;127:659-69. https://doi.org/10.1037/abn0000378.

98. Johns JT, Di J, Merikangas K, Cui L, Swendsen J, Zipunnikov V. Fragmentation as a novel measure of stability in normalized trajectories of mood and attention measured by ecological momentary assessment. Psychol Assess. 2019;31:329-39. https://doi.org/10.1037/pas0000661.

99. Reinertsen E, Clifford GD. A review of physiological and behavioral monitoring with digital sensors for neuropsychiatric illnesses. Physiol Meas. 2018;39:05TR1. https://doi.org/10.1088/1361-6579/aabf64.

100. Egan KJ, Knutson KL, Pereira AC, von Schantz $M$. The role of race and ethnicity in sleep, circadian rhythms and cardiovascular health. Sleep Med Rev. 2017:33:70-8. https://doi.org/10.1016/j.smrv.2016.05.004.

101. Schrack JA, Zipunnikov V, Goldsmith J, Bai J, Simonsick EM, Crainiceanu C, et al. Assessing the "physical cliff": detailed quantification of age-related differences in daily patterns of physical activity. J Gerontol A Biol Sci Med Sci. 2014;69:973-9. https://doi.org/10.1111/biom.12278.

102. Gershon A, Ram N, Johnson SL, Harvey AG, Zeitzer JM. Daily actigraphy profiles distinguish depressive and interepisode states in bipolar disorder. Clin Psychol Sci. 2016;4:641-50. https://doi.org/10.1177/2167702615604613.

103. Goldsmith J, Liu X, Jacobson JS, Rundle A. New insights into activity patterns in children, found using functional data analyses. Med Sci Sports Exerc. 2016;48:1723.

104. Goldsmith J, Zipunnikov V, Schrack J. Generalized multilevel function-on-scalar regression and principal component analysis. Biometrics. 2015;71:344-53. https://doi.org/10.1186/s12888-017-1574-X.

105. Bai J, Sun Y, Schrack JA, Crainiceanu CM, Wang MC. A two-stage model for wearable device data. Biometrics. 2018;74:744-52. https://doi.org/10.1111/ biom.12781. 
106. Di J, Spira A, Bai J, Urbanek J, Leroux A, Wu M, et al. Joint and individual representation of domains of physical activity. Sleep, Circadian Rhythmicity Stat Biosci. 2019;11:371-402. https://doi.org/10.1007/s12561-019-09236-4.

107. Gonzalez R, Gonzalez SD, McCarthy MJ. Using chronobiological phenotypes to address heterogeneity in bipolar disorder. Mol Neuropsychiatry. 2020;5:72-84. https://doi.org/10.1159/000506636.

108. Benard V, Etain B, Vaiva G, Boudebesse C, Yeim S, Benizri C, et al. Sleep and circadian rhythms as possible trait markers of suicide attempt in bipolar disorders: an actigraphy study. J Affect Disord. 2019;244:1-8. https://doi.org/ 10.1016/j.jad.2018.09.054

109. Hwang JY, Choi JW, Kang SG, Hwang SH, Kim SJ, Lee YJ. Comparison of the effects of quetiapine XR and lithium monotherapy on actigraphy-measured circadian parameters in patients with bipolar II depression. J Clin Psychopharmacol. 2017;37:351-4. https://doi.org/10.1097/jcp.0000000000000699.

110. Goldstein TR, Merranko J, Krantz M, Garcia M, Franzen P, Levenson J, et al. Early intervention for adolescents at-risk for bipolar disorder: a pilot randomized trial of interpersonal and social rhythm therapy (IPSRT). J Affect Disord. 2018;235:348-56. https://doi.org/10.1016/j.jad.2018.04.049.

111. Melo PR, Goncalves BS, Menezes AA, Azevedo CV. Circadian activity rhythm in pre-pubertal and pubertal marmosets (Callithrix jacchus) living in family groups. Physiol Behav. 2016;155:242-9. https://doi.org/10.1016/j.physbeh.2015.12.023.

112. Hensch T, Wozniak D, Spada J, Sander C, Ulke C, Wittekind DA, et al. Vulnerability to bipolar disorder is linked to sleep and sleepiness. Transl Psychiatry. 2019;9:294. https://doi.org/10.1038/s41398-019-0632-1.

113. Henriksen TE, Skrede S, Fasmer OB, Schoeyen H, Leskauskaite I, BjorkeBertheussen J, et al. Blue-blocking glasses as additive treatment for mania: a randomized placebo-controlled trial. Bipolar Disord. 2016;18:221-32. https://doi. org/10.1111/bdi.12390.

114. Scott J, Hidalgo-Mazzei D, Strawbridge R, Young A, Resche-Rigon M, Etain B, et al. Prospective cohort study of early biosignatures of response to lithium in bipolar-I-disorders: overview of the H2020-funded R-LiNK initiative. Int J Bipolar Disord. 2019;7:20. https://doi.org/10.1186/s40345-019-0156-x. 